\title{
Evaluating Plant Biodiversity in Natural and Semi-Natural Areas with the Help of Aerial Drones
}

\author{
Dragomir D. SÂNGEORZAN ${ }^{1 *}$ and Ioan ROTAR ${ }^{1}$ \\ ${ }^{1}$ Faculty of Agriculture, University of Agricultural Sciences and Veterinary Medicine Cluj-Napoca, Calea Manastur \\ 3-5, 400372 Cluj-Napoca, Romania \\ * corresponding author: dragomir.sangeorzan@usamvcluj.ro
}

Bulletin UASVM series Agriculture 77(2) / 2020

Print ISSN 1843-5246; Electronic ISSN 1843-5386

DOI:10.15835/buasvmcn-agr: 2020.0007

\begin{abstract}
In the era of abundant information, wisdom has become a scarce resource. Exploration and measurement of biodiversity yield copious amounts of information fragmented into numerous categories and types, following the pattern of life itself. We aim to review the potential of charting the plant diversity of woodlands, grasslands, marshlands, and other natural and semi-natural areas relevant to conservation by using low-altitude, low-cost, Earth Observation technology, such as small aerial drones, that captures images which can be mapped and analyzed. As this technology is new and quickly evolving, we limited the search to published research between 2012-2019. We have found applications for forestry, agro-forestry, horticulture, grasslands, ecological restoration, and other areas. In terms of technological progress, new hardware components and cameras and new software tools leverage drones' power to deliver a greater quantity and quality of information. There are promising efforts to develop low-cost drone technology that facilitate better biodiversity conservation results. For analysis, software tools are also improving to take advantage of increases in computing power and artificial intelligence programming. Our findings serve as an introduction to low-cost teledetection for biodiversity conservation, with drones providing an advantage in monitoring habitats by increasing information quantity, accuracy, and ease of analysis with the aid of automation.
\end{abstract}

Keywords: biodiversity, drones, earth observation, habitat conservation

\section{INTRODUCTION}

As the United Nations Decade on Biodiversity (2011-2020) nears its end (CBD, 2018), we can use its efforts to underline the importance of having specific goals and plans to achieve goals such as the Aichi Biodiversity Targets. One of the critical components of these plans has been and will continue to be providing data for management based on the ability to measure biodiversity, mostly plant diversity in unique habitats, creating the evidence needed to maintain and expand protected areas.

Monitoring terrestrial biodiversity at a large scale has been achieved, to a degree, with a specific type of Earth Observation (EO) that focuses on using Tele-detection (TD) or Remote
Sensing to understand biological features. Crewed and crewless aerial missions were necessary, as the technology has evolved since the 19th century. However, light and crewless vehicles carrying only recording tools have been essential in advancing this field. From balloons, kites, planes, and even pigeons, EO's early history has shown great interest in the UAV (Baumann, 2001). The highresolution imagery with spatial and temporal references allows for the implementation of advanced photogrammetry and Computer Vision (CV) software tools to merge photos into highquality models and maps (Colomina and Molina, 2014). This technological progress has allowed researchers to obtain powerful 3D models of forests using photogrammetry instead of the 
more costly Light Detection and Ranging (LIDAR) technology (Lisein et al., 2013). Anderson and Gaston (2013) predicted that the use of Unmanned Aerial Vehicles (UAVs) could provide imagery of sufficient quality to be useful for spatial ecology by having high-resolution data that is spatially referenced and by consistently monitoring areas over time, all at a reasonable cost. Shahbazi et al. (2014) produced a broad review of UAV usage for natural and agricultural areas, showing that many applications were being deployed. However, the technology was in its early phase, and the research was insufficiently transdisciplinary. Five years later, Jiménez López and Mulero-Pázmány (2019) reviewed general biodiversity conservation applications with drones and found that aerial drone technology was useful in conservation efforts. Our paper focuses on how terrestrial vegetation diversity in natural and semi-natural habitats, from trees to grasses, can be measured with one category of UAVs. These drones are accessible in terms of cost, technical know-how, and security concerns (Ivošević et al., 2015). They can be described as small aerials vehicles that fly at low altitudes and can carry a digital RGB camera (cam) or other imaging sensors, along with other technology required for geospatial mapping.

\section{MATERIALS AND METHODS}

We chose a broad search criterion in order to do an extended search of the literature. Drone-based biodiversity research was uncommon at the time, even if the scope extended to non-peer-reviewed research. Studies were included in the scope if they relied on the use of drones to capture aerial footage of a habitat and focused on analyzing the vegetation of that landscape. Studied areas had to be natural or semi-natural to maintain the focus on biodiversity. However, we included some studies that focused on orchards too, as they are similar in methodology to the study that researched forests and provided more nuance. We mapped each paper into a standardized entry containing sub-fields of information representing a shared methodology and scope in all articles to sort out the relevant information for our investigation. We summarized the aims, methodologies, results, and conclusions of the studies to have standard, measurable, and comparable entries. We represented the methodological aspect as brief technical details when they were available; any missing bit of information was left out of the entry, even if apparent deductions were possible.

The relevant technical aspects we recorded: the area - an essential variable for each flight; the type of UAV (with fixed-wing or with multiple rotors); the resolution of the digital camera, in megapixels; the target flight altitude (ALT); the ground sampling distance (GSD) - the measure of captured detail; type of methodology applied for processing the data post-flight.

Finally, the results of each study were summarized relative to their aims. However, each result was relevant to our paper's overall question, and we presented them as short descriptions.

\section{RESULTS AND DISCUSSIONS}

We synthesized studies that used drones to map and measure vegetation, biodiversity, or some natural landscape features into Table 1 . In the case of Koh and Wich (2012), the study was included for the sake of its canopy charting methodology that surveyed the orangutan in its natural habitat. The studies by Zarco-Tejada et al. (2014) and Singh and Nansen (2017) were also included for their methodology focusing on large vegetation, despite being areas with a higher degree of hemeroby.

The studies we analyzed managed to survey five main types of landscapes, representing a wide variety of natural and semi-natural habitats (Figure 1a).

Our results match those of Jiménez López and Mulero-Pázmány (2019) on the use of low-cost UAV technology, such as drones equipped with RGB cameras, to provide data for biodiversity conservation efforts.

The success of aerial surveys depends mainly on the quality of the produced images. Considering standard flight practices that increase accuracy and reduce errors, the core variables remain camera resolution and flight altitude. This technology's feasibility is likely to increase in power (Tang and Shao, 2015) and accessibility (Ivošević et al., 2015). Our study revealed an average $13,66 \mathrm{Mpx}$ camera sensor, a value that reflects the demands for low-cost technology, as the researchers more commonly used consumer-grade and semiprofessional cameras for their UAVs. As of 2018, camera sensor technology has improved at this market level, allowing for better resolution for compact cameras (DoubleMesh.com, 2017). The more this technology improves in terms of cost 
Table. 1. Studies that used drone-based footage to analyze wild habitats or orchards compiled and reworded to show our investigation's relevant details.

\begin{tabular}{|c|c|c|}
\hline Study & Aim and Methods & Results and Conclusion \\
\hline al & $\begin{array}{l}\text { Aim: Test aerial drone survey by mapping a forest } \\
\text { area. Area: deciduous forest. UAV: quadcopter }+14.2 \\
\text { Mpx cam. Flight: } 250 \mathrm{~m} \text { ALT / } 43 \mathrm{~mm} \text { GSD. Method: } \\
\text { aerophotogrammetry mapping }\end{array}$ & $\begin{array}{l}\text { The aerial survey was successful, useful } \\
\text { in mapping biodiversity, and cost- } \\
\text { effective, but was less accurate than the } \\
\text { ground survey. }\end{array}$ \\
\hline $\begin{array}{l}\text { (Koh and } \\
\text { Wich, 2012) }\end{array}$ & $\begin{array}{l}\text { Aim: Monitor Sumatran orangutan population. Area: } \\
\text { tropical rainforest. UAV: Fixed wing (FW) + } 12 \text { Mpx cam. } \\
\text { Flight: } 100 \mathrm{~m} \& 180 \mathrm{~m} \text { ALT / } 22 \mathrm{~mm} \& 74 \mathrm{~mm} \text { GSD. Method: } \\
\text { aerophotogrammetry mapping. }\end{array}$ & $\begin{array}{l}\text { rvey allowed the } \\
\text { of large mammals } \\
\text { elephant). This technology } \\
\text { rchers to monitor large } \\
\text { trees. }\end{array}$ \\
\hline $\begin{array}{l}\text { (Dandois } \\
\text { and Ellis, } \\
\text { 2013) }\end{array}$ & $\begin{array}{l}\text { projection } \\
\text { forest. UAV: } \\
\text { m ALT. Method: } \\
\text { it cloud modeling. }\end{array}$ & $\begin{array}{l}\text { erial survey provided a model } \\
\text { tas slightly less accurate than } \\
\text {. }\end{array}$ \\
\hline $\begin{array}{l}\text { (Zarco- } \\
\text { Tejada et } \\
\text { al., 2014) }\end{array}$ & $\begin{array}{l}\text { ng of tree height. } \\
12 \text { Mpx color infrared } \\
\text { Im GSD. Method: } \\
\text { int cloud modeling. }\end{array}$ & $\begin{array}{l}\text { The aerial survey provided } \\
\text { measurements as accurate as g, } \\
\text { measurements and similar to L } \\
\text { measurements. }\end{array}$ \\
\hline $\begin{array}{l}\text { (Puttc } \\
\text { al., } 20\end{array}$ & $\begin{array}{l}\text { Aim: Monitor beaver impact on the environment. } \\
\text { Area: wetland, river catchment. UAV: hexacopter + } \\
\text { 12.1 Mpx cam. Flight: } 25 \mathrm{~m} \text { ALT / 10mm GSD. Method: } \\
\text { aerophotogrammetry mapping, point cloud modeling, } \\
\text { manual classification }\end{array}$ & $\begin{array}{l}\text { The aerial survey allowed for the } \\
\text { identification of dams and other beaver } \\
\text { effects on the area. The classification } \\
\text { was successful but too complex for } \\
\text { automation. }\end{array}$ \\
\hline
\end{tabular}

Aim: Monitor flora and assess biodiversity with low-cost

(Gallacher methods. Area: rangeland, desert. UAV: octocopter +24

et al., 2016) Mpx cam. Flight: $10 \mathrm{~m}, 30 \mathrm{~m}, 100 \mathrm{~m}$ ALT / $2 \mathrm{~mm}, 6 \mathrm{~mm}$, 20mm GSD. Method: manual classification

The aerial survey allowed for $70 \%$ successful classification at $2 \mathrm{~mm}$ GSD and $40 \%$ successful classification at $20 \mathrm{~mm}$. The results had less precision but covered a larger area.

(Watson, Aim: Plant classification for restoration management. 2016) Area: Grassland. UAV: quadcopter + $12 \mathrm{Mpx}$ cam. Flight: 2m \& 5m ALT. Method: manual classification

The aerial survey was successful but revealed fewer species than the ground survey. The results had less precision but covered a larger area.

Aim: Test drone technology for forest area mapping.

(Zhang et Area: forest. UAV: quadcopter + 14.2 Mpx cam. Flight:

al., 2016) 240m ALT / 43mm GSD. Method: aerophotogrammetry mapping, 3D mapping

The aerial survey was useful in mapping biodiversity by providing high-quality data about the forest's vertical structure.

Aim: Map forest cover. Area: deciduous forest. UAV:

(Banu et al., quadcopter + 12 Mpx cam. Flight: 140m ALT / 51.8mm

2017) GSD. Method: aerophotogrammetry mapping, uniform The aerial survey model of forest cover matched the ground survey, providing useful data with a modest drone and segmentation, manual classification fewer work hours.

(Singh and Aim: Evaluate the light calibration system to improve Nansen, imagery. Area: orchard. UAV: octocopter + spectral 2017) imager. Flight: 50m ALT / 4mm GSD. Method: spectral analysis

The calibration system decreased variance, allowing for better classification accuracy.

Aim: Explore the relationship between vegetation and (Lyons et dune morphology. Area: desert. UAV: quadcopter + al., 2018) 12.4 Mpx cam. Flight: 70m. ALT / 30 mm GSD. Method: aerophotogrammetry mapping, statistical analysis
The aerial survey allowed for the successful mapping of vegetation and dunes, providing evidence for a nuanced relationship. Better GPS accuracy in this remote location would have improved results. 


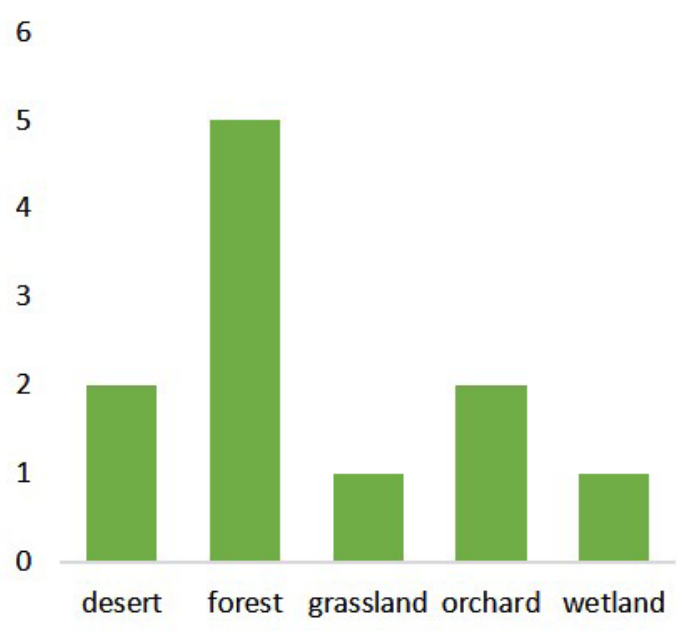

a

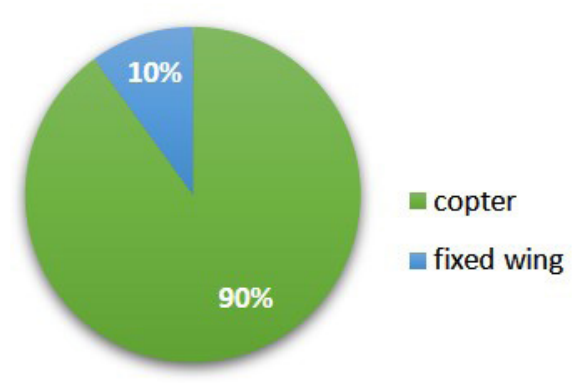

b

Figure 1. Area type distribution showing the frequency of type of studied areas (a), drone type ratio showing usage of differing drone classes (b)

per pixel, the more it will allow research drones to improve classification work and coverage. The GSD is the relevant variable in this discussion, with the average values ranging from $22.80 \mathrm{~mm}$ to $25.07 \mathrm{~mm}$, and with $2 \mathrm{~mm}$ as the smallest used value (Gallacher et al., 2016) as an extreme outlier. Because the average flight altitude was between $102 \mathrm{~m}$ and $119 \mathrm{~m}$, the researchers had to sacrifice accuracy or enlarge the experiments' scope and scale.

Most of the flown UAVs were multicopter (Figure 1b) that are better suited for producing high-quality imagery due to their capacity to fly slower and at lower altitudes. At the same time, fixed-wing drones require minimum speeds in order to maintain altitude. If camera resolution technology improves further, UAVs may become the favored drone type, as they can fly further and higher, allowing for monitoring of larger biotopes than what is possible with multicopters. The main technological challenges revolve around packing more and better sensors and supporting tools in smaller drones. Optical sensors have shown significant progress over the years, increasing camera resolution and stability while maintaining or shrinking in size. The batteries are the other challenge, and they are a key limit for all electrified vehicles. The standard Li-ion batteries are used at their technological limits and allow for relatively short flights while packing considerable weight on the aircraft. Emerging technologies such as
Li-Sulphur and Li-air may provide more energy storage per unit of weight if they reach the market (Blagoeva et al., 2019).

The most investigated type of landscape was forest ( 5 studies), which is also the most feasible application for drone-based monitoring due to vegetation's significant features. The other types of areas can be grouped into the same category of difficulty, as they contain smaller forms of vegetation and required flights at lower altitudes. Getzin et al. (2019) used drone aerophotogrammetry to successfully investigate the ecology of an arid grassland, using spatial pattern analysis to determine ecological relationships at the ground scale, demonstrating the use of this technology with greater magnitude of detail.

The post-processing of images is a very significant part of the working process. The authors employ various procedures and tools to achieve their aims of analyzing the vegetation of an area by mapping its features. These procedures may be ranked in terms of complexity: manual counting and classification without trying to build a digital representation of the area, computer-assisted classification and segmentation of imagery, building 3D models with aerophotogrammetry mapping integrated with Geographic Information System (GIS) systems, point-cloud modeling with Computer-Vision based software. Various authors within the scope of the studies we investigated used machine-learning technology to build point- 
clouds as a standard practice. More complex Machine-Learning (ML) types were available and were not used in the investigated studies, such as Convolutional Neural Networks used for image classification - a promising tool for future research with drone-based aerial imagery, but beyond the scope of this review.

\section{CONCLUSION}

Due to the reports of success in each study, we must be wary of publishing bias, as this research topic is still emerging, and we could not find null results in the peer-reviewed literature. All the studies we checked encountered challenges. However, they reported modest to high success relative to their goals, providing evidence that biodiversity, at the level of trees, shrubs, and grasses, can be assessed directly or indirectly by relying on aerial footage from drones along with software analysis.

\section{REFERENCES}

1. Anderson K, Gaston KJ (2013). Lightweight unmanned aerial vehicles will revolutionize spatial ecology. Frontiers in Ecology and the Environment, 4(11): 138-146.

2. Banu TP, Borlea GF, Banu C (2017). Determination of the forest canopy cover using a low-cost commercial drone in a turkey oak and durmast oak stand in the Zarand Mountains, Romania. Research Journal of Agricultural Science, 49: 12-17.

3. Baumann P (2001). History of remote sensing, aerial photography. State University of New York. Consultado, Volume 24.

4. Blagoeva D, Pavel C, Wittmer D, Huisman J, Pasimeni F (2019). Materials dependencies for dual-use technologies relevant to Europe's defence sector. EUR 29889: 213-225.

5. CBD S (2018). The United Nations Decade on Biodiversity. Available at: https://www.cbd.int/2011-2020 Accessed 20.02.2018.

6. Colomina I, Molina P (2014). Unmanned aerial systems for photogrammetry and remote sensing: A review. Journal of Photogrammetry and Remote Sensing, 6(92): 79-97.

7. Dandois JP, Ellis EC (2013). High spatial resolution threedimensional mapping of vegetation spectral dynamics using computer vision. Remote Sensing of Environment, 9(136): 259-276.

8. DoubleMesh.com (2017) Ten Best Cheap Cameras: Affordable Photography Cameras. Available at: https:// www.doublemesh.com/best-cheap-cameras Accessed 20.02.2018.

9. Gallacher D, Khafaga MT, Ahmed MTM, Shabana MHA (2016). Plant species identification via drone images in an arid shrubland. s.l., 10th International Rangeland Congress, pp. 1024-1025.

10. Getzin S, Wiegand K, Schöning I (2012). Assessing biodiversity in forests using very high-resolution images and unmanned aerial vehicles. Methods in Ecology and Evolution, 4(3): 397-404.

11. Getzin S, Yizhaq H, Muñoz-Rojas M, Wiegand K, Erickson TE (2019). A multi-scale study of Australian fairy circles using soil excavations and drone-based image analysis. Ecosphere, 2(10): e02620.

12. Ivošević B, Han Y-G, Cho Y, Kwon O (2015). The use of conservation drones in ecology and wildlife research. Journal of Ecology and Environment, 38: 113-118.

13. Jiménez López J, Mulero-Pázmány M (2019). Drones for Conservation in Protected Areas: Present and Future. Drones, 1(3): 10.

14. Koh LP, Wich SA (2012). Dawn of drone ecology: low-cost autonomous aerial vehicles for conservation. Tropical Conservation Science, 5: 121-132.

15. Lisein J, Pierrot-Deseilligny M, Bonnet S, Lejeune P (2013). A Photogrammetric workflow for the creation of a forest canopy height model from small unmanned aerial system Imagery. Forests, 12(4): 922-944.

16. Lyons MB, Mills CH, Gordon CE, Letnic M (2018) Linking trophic cascades to changes in desert dune geomorphology using high-resolution drone data. Journal of the Royal Society Interface, 15(144).

17. Puttock AK, Cunliffe AM, Anderson K, Brazier RE (2015). Aerial photography collected with a multirotor drone reveals impact of Eurasian beaver reintroduction on ecosystem structure. Journal of Unmanned Vehicle Systems, 3: 123-130.

18. Shahbazi M, Théau J, Ménard P (2014). Recent applications of unmanned aerial imagery in natural resource management. GIScience \& Remote Sensing, 51: 339-365.

19. Singh KD, Nansen C (2017). Advanced calibration to improve robustness of drone-acquired hyperspectral remote sensing data, 6th International Conference on Agro-Geoinformatics, Institute of Electrical and Electronics Engineers, pp. 1-6.

20. Tang L, Shao G (2015) Drone remote sensing for forestry research and practices. Journal of Forestry Research, 12(26): 791-797.

21. Watson D (2016). Biodiversity restoration-can drones provide an accurate, efficient and safe survey method? Quarry Life Award final project report. HeidelbergCement.

22. Zarco-Tejada PJ, Diaz-Varela R, Angileri V, Loudjani $P$ (2014). Tree height quantification using very high resolution imagery acquired from an unmanned aerial vehicle (UAV) and automatic 3D photo-reconstruction methods. European Journal of Agronomy, 4(55): 89-99.

23. Zhang J, Hu J, Lian J, Fan Z, Ouyang X, Ye W (2016). Seeing the forest from drones: Testing the potential of lightweight drones as a tool for long-term forest monitoring. Biological Conservation, 6(198): 60-69. 